\title{
THE USEFULNESS OF MARKETING STRATEGIES IN A REGULATED MARKET: EVIDENCE FROM THE SPANISH TOBACCO MARKET
}

\section{Alejandro Almeida ${ }^{1}$, Aida Galiano ${ }^{2}$, Antonio A. Golpe Juan Manuel Martín Álvarez ${ }^{4}$}

1 International University of La Rioja (UNIR), Faculty of Business and Communication, Spain, ORCID: 0000-00016490-4998, alejandro.almeida@unir.net;

2 International University of La Rioja (UNIR), Faculty of Business and Communication, Spain, ORCID: 0000-00021587-6262, aida.galiano@unir.net;

University of Huelva, Spain, ORCID: 0000-0003-0360-1541, antonio.golpe@dehie.uhu.es;

4 International University of La Rioja (UNIR), Faculty of Business and Communication, Spain, ORCID: 0000-00027315-9827, juanmanuel.martin@unir.net.

\begin{abstract}
This paper outlines possible useful marketing strategies for companies to develop in a regulated market. The empirical analysis aims to highlight whether companies can use marketing strategies to create competitive advantages and scale positions in sales leadership once regulation policies are introduced. To this end, we apply two econometric approaches to sales variables for 138 best-selling cigarette brands: the Bass Model (1969) to estimate the parameters that determine the way clients adopt, and the methodology proposed by Hartigan and Wong (1979) for a further cluster analysis that groups brands. The empirical results suggest that restrictions on demand introduced to the Spanish tobacco market during the years 2005 and 2006, have generated a new scenario in which innovation parameters have no effect on the process of adoption. Therefore, the imitation coefficient is the parameter which makes discrimination between brands possible, which demonstrates the existence of heterogeneity among brands based only on recommendation. The results show the inability of direct marketing strategies to create advantages and scale positions in sales leadership after the introduction of regulation policies, however companies have other marketing options such as imitation among clients and these have proven to be effective since imitation shows heterogeneous behaviour among brands across the diffusion process. This has implications that should be taken into account in markets which are on the verge of being regulated, specifically the modification of marketing strategies if the intention is to lead and scale position in a regulated market. In particular, in the case of Spain, policymakers must acknowledge that the measures implemented in law 28/2005 have had an effect on marketing strategies by cancelling, in practical terms, the diffusion of brands based on innovation and homogenizing the diffusion process based on direct marketing.
\end{abstract}

Keywords: Marketing strategies, tobacco market, regulated market, diffusion process, Spain.

JEL Classification: L53, L66, M31, M38.

APA Style Citation: Almeida, A., Galiano, A., Golpe, A. A., \& Martín Álvarez, J. M. (2021). The Usefulness of Marketing Strategies in a Regulated Market: Evidence from the Spanish Tobacco Market. E\&M Economics and Management, 24(2), 171-188. https://doi.org/10.15240/ tul/001/2021-2-011 


\section{Introduction}

In the current economy, there are some heavily regulated markets, such as the tobacco market, and others on the point of being regulated markets using fossil combustibles, such as the combustion engine vehicles, as well as the gambling sector. Those markets operate with products or services in some way prejudicial to health and the environment. This fact justifies before the citizens the governmental intervention. Companies operating on those markets have very limited their marketing strategies to promote sells (Henriksen, 2012). In this article, we aim to investigate the options faced by companies for the implementation of marketing strategies that will permit them to scale their sales leadership position once the market is regulated.

In the case of the tobacco market, the motivation to regulate emerges due to the causal link between tobacco consumption and several types of cancer, cardiovascular and respiratory diseases, reproductive disorders, Alzheimer's disease (López-Arrieta \& Sanz, 2001), and many other negative health consequences. In addition, it has an addictive nature (DHSS, 2004).

Some demand restrictive laws have been applied with the objective of limiting the consumption of this harmful and addictive product (Pinilla et al., 2019). Policy makers and academics have worked out different ways to control its sales, in order to manage the levels of tobacco consumption. For instance, on the demand side, by passing laws that prohibit smoking or impact price taxation (Contreary et al., 2015). On the supply side, restrictions include banning manufacturers of tobacco products and retailers from maintaining prices to promote tobacco products to keep demand high (Escario et al., 2004; Pinilla \& Abásolo, 2017).

In recent years, the Spanish government has successfully brought into forceied several restrictive laws to control the legal sales of cigarettes. Specifically, the Spanish smokingfree laws of 2005 had an effect on consumption by introducing restrictions on the demand side. The 28/2005 law (December 26), introduces antismoking sanitary measures that regulates the sale, supply, consumption and advertising of tobacco products. Published in BOE number 309 of December 27, 2005 (Effective since January 1, 2006 and revised on November 19,
2017) this law introduces harsh restrictions on marketing strategies banning the advertising, promotion and sponsorship of tobacco outside of an establishment authorized for selling under a monopoly regime.

The different laws affecting the Spanish tobacco market from 2005 have been analysed from different perspectives by academics. Some research state the effects on the prevalence of smokers and tobacco sales (Pinilla \& Abásolo, 2017; Pinilla et al., 2019; Pons et al., 2019). By contrast, other studies have focused the results of exposure to environmental tobacco smoke (Fernández et al., 2015; Galán et al., 2007). However, none of these investigations focus on the marketing strategies developed under tacit obligation since the application of the laws, particularly since the 28/2005 law, which affected direct marketing strategies head on.

Our paper focus on the difficulties that companies face in developing useful marketing strategies in a regulated market. Consequently, our empirical analysis aims to answer the following research question: Can companies use marketing strategies to create advantages and scale positions in sales leadership once regulation policies are introduced? If the answer to the research question is affirmative, this will have strong implications for future regulated markets, warning companies about the necessity to scale positions before being regulated.

To reach our research objective, monthly sales from January 2005 to October 2018 of the 138 best-selling brands of cigarettes have been analysed applying two different but complementary methodologies. First, we use the method developed by Mahajan et al. (1995) for applying the Bass Model to uncover the innovation coefficient value $(p)$ and the imitation coefficient $(q)$ in the diffusion process of the Spanish tobacco market. The Bass Model (1969) is the formal explanation of the decision-making process that leads to product adoption in the market, caused by the interaction between actual or adoptive clients and potential clients or adopters. In support of what certain authors have argued regarding the influence of external factors on sales, it seems reasonable to use the Bass Model to uncover whether the diffusion process of certain products is conditioned by regulatory changes affecting sales. The advantage of using this particular diffusion model is that it estimates 
two informative parameters indicating what factors contribute to the diffusion process of the product. On the one hand, the parameter $(p)$, also called the innovation coefficient, external influence or advertising effect. On the other hand, the parameter (q), known as the imitation coefficient or internal influence. The parameter (q) reflects a type of diffusion through the sharing of experiences - so called word-of-mouth effect - therefore, it is based on a combination of personal relationships. Along these lines, many studies estimate (p) and (q) for services, sectors and products of different nature (Alonso \& Arellano, 2015; Ratcliff, 2016; Lavasani \& Du, 2016; Song et al., 2016; Ayavirina et al., 2017). In section 1.1 we provide a brief overview of the different types of products used in previous literature to study the diffusion process. To the best of our knowledge, the Bass Model has not been used in previous literature to measure the effectiveness of demand-restricting laws and, particularly, to conclude how these laws affect marketing strategies.

Second, we follow the methodology proposed by Hartigan and Wong (1979) to develop a clusters analysis that groups the different brands according to the estimated values of the $p$ and $q$ parameters. The purpose of using this methodology is, first, to identify the relevant parameter in the adoption process after the introduction of restrictive laws and, second, to group brands of cigarettes so as to identify different behaviours and signal the way restrictive laws affect consumption. The cluster analysis allows us to determine whether the imitation or innovation coefficients are parameters that help to discriminate between products in different groups whilst capturing the heterogeneity among different brand groups. Such heterogeneity will reveal the use of different marketing strategies, while homogeneous behaviour will point to the impossibility of differentiating by using marketing alternatives.

The objective of the research is to conclude how the law 28/2005 has affected marketing strategies and the possibilities for companies operating in a regulated or about to be regulated market. Specifically, we compare different brands in order to observe whether heterogeneous behaviour revealing different marketing strategies exists or, by contrast, whether homogenous behaviour exists indicating the impossibility of differentiation using marketing strategies. If heterogeneous behaviour is demonstrated the answer to the research question will be positive, implying that companies cannot scale position to be a leader in the market by using marketing strategies after the introduction of the market-regulating policy. Furthermore, by distinguishing the two parameters of the Bass Model, their magnitude and how they cluster, we shall be able to reveal possible future marketing strategies for companies faced by restrictive laws.

In this sense, there are previous findings regarding the limitations of tobacco product marketing. First, a recent study shows that exposure patterns for cigarette and vaping product marketing generally reflect countryspecific policies (Cho et al., 2020), meaning the analysis focused on a single country (Spain) appears consistent with previous literature. In this sense, it seems that anti-smoking laws reduce exposure to marketing influences (Harris et al., 2006; Craig et al., 2020; Kasza et al., 2011), resulting in an improvement in behaviors related to smoking (El-Toukhy et al., 2018). From a marketing point of view, there is evidence that when tobacco advertising is banned there are significant decreases in knowledge about tobacco products (Moodie et al., 2008; Henriksen, 2012). This lack of knowledge about tobacco products seems to generate market concentration (Mirza, 2019).

\section{Theoretical Framework}

\subsection{Bass Model Applications}

In this section, we have provide an overview of previous empirical findings that used the Bass diffusion model (Bass, 1969) for different applications. In this search, we corroborate that the diffusion models, and specifically the Bass methodology, has been applied to products of a different nature.

The basic Bass Model is a durable quality diffusion model. The case of color TV replacing black and white TV (Bayus, 1992) is the iconic example of Bass Model application to durable goods. However, Dolan and Jeuland (1981) studied both durable and non-durable goods based on the Bass Model extension (Bass, 1980).

In recent times, new products have been studied using this methodology (Mahajan et al., 2000). Since the pioneer papers on technological innovation (Bass, 1980; Bass et al., 1982), alternative papers have analysed 
the diffusion pattern of technological products and services by using diffusion models (Weissmann, 2008; Alonso \& Arellano, 2015). The heterogeneity in the diffusion process is also considered in Alonso and Arellano (2015) by entering socio-demographic variables which verify the heterogeneity in the diffusion process in the digital economy for the Spanish market based on age and education. Some services inside the technological and connected economy have also been included, such as the diffusion of the instant messaging market (Jiang, 2017) or the types of internet connections such as broadband whose diffusion processes have been studied across the EU countries by Turk and Trkman (2011).

Other papers focus on a particular economic sector, such as tourism, vehicles - combustion and plug-in electric vehicles, the renewable energy technologies sector, or a particular industry such as the game industry (Song et al., 2016). Papers based on the energy sector focus on renewable energy technologies (Usha Rao \& Kishore, 2010; Joga Rao et al., 2016) and, particularly, plug-in electric vehicles (Lavasani et al., 2016; Gnann, 2018; Mersky et al., 2016; Sierzchula et al., 2014). The objective of these research projects is to review market diffusion patterns for these types of products, while other articles consider the effects of policy incentives to promote such products (Long et al., 2016) via demand-expanding policies. In that paper Long et al. (2016) find that potential adopters are concerned about the relative cost compared to the conventional car, and quantify the effect of relevant variables such as the cost of public charging stations. Regarding the tourism sector, Ayaviri Nina et al. (2017) focus on feedback from tourists who have visited a particular site or place, they use the Bass Model to estimate tourist expectations.

This branch of the literature focuses on emerging markets while the Bass Model has always been applied to mature markets. In this respect, Porath and Schaefer (2014) outline a good performance of the Bass Model in emerging markets.

All this research has the same purpose, to review the diffusion and the adoption process of a product that has been introduced into the market. Having revised the literature, the authors emphasize that products of a diverse nature are analysed by using diffusion models, in particular, the Bass methodology.

\subsection{The Tobacco Market and Previous Empirical Findings Relating to Tobacco Control Laws in Spain}

In order to contextualize the objective of our research, and to justify the focus on the case of Spain, we start by reviewing the characteristics of the Spanish tobacco market. This is a significant analysis since the Spanish market has several particularities due to the events of recent years.

First, the Spanish government authorizes the sale of monopoly tobacco products for both cigarettes and roll-your-own (RYO) cigarettes. Although RYO has increased in importance in recent years, as shown in Fig. 1, cigarettes are the most representative tobacco product during the entire period studied (from 2005 to 2018). Thus, the focus of the analysis is on cigarettes, and by doing so we consider approximately $90 \%$ of the Spanish tobacco market.

Second, as in most developed countries, the Spanish government has been very concerned with the health problems caused by tobacco consumption, so that different restrictive laws have been applied to control tobacco consumption and its promotion. On April 11, 2005, Spain ratified the agreements of the World Health Organization Framework Convention on Tobacco Control (WHO, 2003). The WHO-FCTC is the first international health treaty that requires parties to implement tobacco control measures. Consequently, on January 1 , 2006, the first national law banning smoking came into force. This law was a turning point in the regulation of promotional activities, and it set the basis for future advancement strategies, following the direction established by the European and the International Community. Specifically, this law limits the sale, supply, consumption and promotion of tobacco and it has the fundamental objective of making tobacco products less accessible and less attractive to the population. In practical terms, law 28/2005 banned, since its introduction, the advertising, promotion and sponsorship of tobacco outside an establishment authorized for the sale of retail tobacco under a monopoly regime.

Since the law 28/2005 came into place, many studies developed their analysis on the effect of tobacco (sales of cigarettes). First, there are projects that studied the effects on the prevalence of smokers and tobacco sales (Pinilla \& Abasolo, 2017; Pinilla et al., 


\section{Fig. 1: Evolution of Spanish tobacco market}

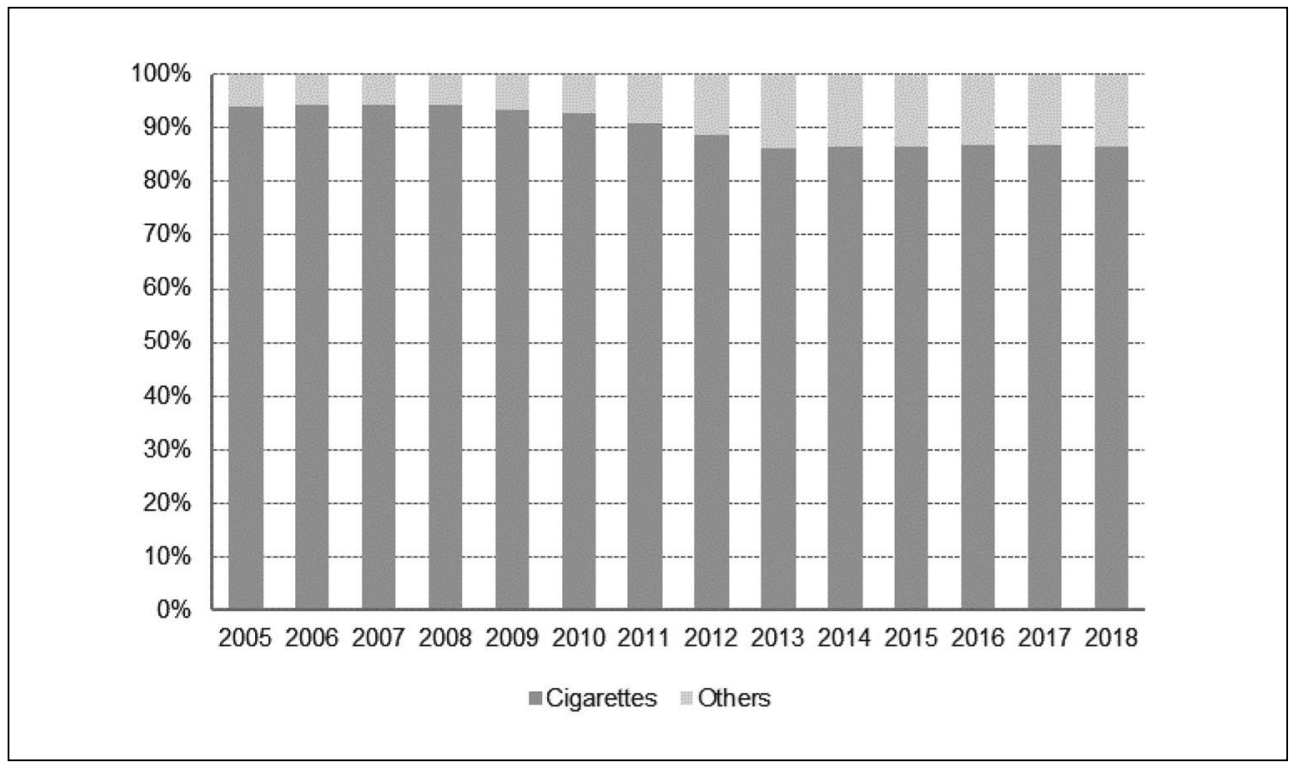

Source: own

2019; Pons et al., 2019). In this first block, it seems that there is a common conclusion: law $28 / 2005$, which restricts advertising, promotion and sponsorship and prohibited smoking in certain places, has no effect on the volume of sales of cigarettes. Second, other studies have focused on exposure to environmental tobacco smoke, that is, to assess the impact of these laws on passive smoking (Fernández et al., 2015; Galán et al., 2007; Jiménez-Ruiz et al., 2008; Ruiz et al., 2014). This second group of papers suggests that the anti-smoking law produced a considerable reduction in exposure to environmental tobacco smoke in the workplace and, to a lesser extent, in bars and restaurants. In summary, although it had no influence on total sales, this law was effective in minimizing exposure to tobacco smoke by nonsmokers.

However, none of these articles considered the effect of the aforementioned law on the diffusion of tobacco products. Since one of the objectives of the regulation is to make tobacco less attractive and accessible to the population, we understand that it is important to analyse how the law has influenced the diffusion of cigarettes. Additionally, given that law 28/2005 restricts smoking in certain places but also limits advertising, promotion and sponsorship, it is interesting to know how measures that limit marketing actions have influenced the diffusion of tobacco products. This paper studies the effect of restrictive laws introduced in the Spanish tobacco market, concretely the $28 / 2005$ law, and its influence on the diffusion of cigarette brands.

Summarizing both branches of literature (Bass Model research and articles analysing government intervention laws on the tobacco market), we found no evidence of any research focusing on the effect of demand-restricting laws on the way companies use marketing actions in the diffusion process. Therefore, our research question focuses, in the particular case of the Spanish tobacco market, on whether hierarchy in the market is consolidated and perpetuated because of the inability of companies to use direct marketing actions to create competitive advantages. We address the research question as follows:

$R Q$ : Can companies use marketing strategies to create advantages and scale positions in sales leadership once regulation policies are introduced? 
Therefore, the objective of the analysis in answering this question is guided by the following hypotheses:

H1: Companies have options to implement direct marketing actions allowing them to scale positions in sales leadership after the introduction of restrictive demand laws.

H2: The hierarchy in the market is consolidated and perpetuated once the market is regulated because of the inability of companies to use promotion and advertising to create advantages.

H3: Brands are not able to use marketing strategies in general to position themselves as leaders in the tobacco market.

\section{Methodology}

\subsection{Data}

We develop a time series analysis of the 138 best-seller tobacco brands. Specifically, we use monthly time series for sales from January 2005 to October 2018 published by the Trade of Tobacco Commission (Comisionado para el Mercado de Tabacos) - an autonomous body created by law $13 / 1998$, to safeguard neutrality and free competition inside the Tobacco market within the national territory. Our research period and sample size have been selected to incorporate the greatest amount of information in our analysis given the peculiarities of the database.

Fig. 2 presents a graphical analysis of the time series dynamics plotted for total cigarette sales in which a decreasing trend across the period of analysis is evident. The beginning of the 2005 and 2010 laws has been marked because both had a negative effect on cigarette sales, the effect of the 2010 law being more pronounced. (Martín Álvarez et al., 2020a).

However, within the sample used, there are brands experiencing increased sales, decreased or stable, regardless of the global trend. Therefore, it is necessary to study the behaviour of each one of the 138 best-seller brands in order to observe heterogeneous behaviours.

\subsection{The Adoption Process in the Tobacco Market (The Bass Model, 1969)}

To quantify the speed of adoption of a new product in the market and in order to analyse

\section{Fig. 2: Evolution of total sales (in millions of packs)}

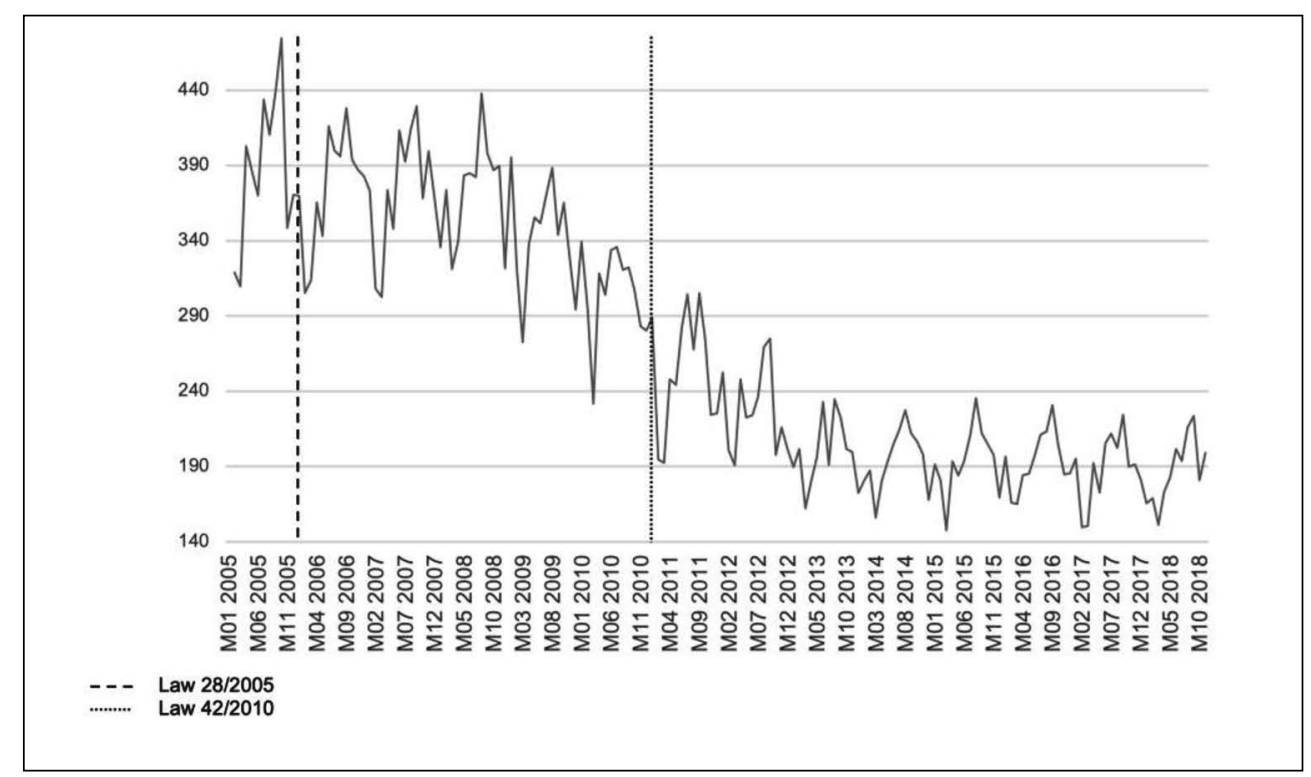


the factors underpinning the adoption process, the Bass Model (1969) is used. The basic assumption of the model is that the timing of a consumer's initial purchase is related to the number of previous buyers. A behavioural rationale for the model is offered in terms of innovative and imitative behaviour. The process of modelling the diffusion of new products is explained in the work carried out by Mahajan et al. (1995).

The Bass Model (1969) is a mixed diffusion model that explains the adoption process considering external effects (innovation or publicity) and internal effects (imitation or recommendation). Thus, it represents a modelling of mixed influences (external and internal) and estimates them by quantifying the value of two parameters, which are called the adoption coefficients:

$p$ : The coefficient of innovation or advertising effect. We will conclude that the speed of adoption of a new product due to the effect of innovation is faster in those products where this coefficient is higher.

$q$ : The imitation factor or contagion effect. Those products where this coefficient is higher are in the growth phase, since they are producing an expansion process by contagion, compared to those products where this factor is lower. Lower values of $q$ correspond to a mature market.

The main objective of the Bass diffusion model is to describe a pattern of spread of innovation among potential adopters in terms of a mathematical function of time (Kijek \& Kijek, 2010). So, we start from the distribution function $F(t)$ that represents the adoption in period $t$, and its associated density function $f(t)$. From them, and following a hazard rate (chance function), the probability of an individual to adopt for the first time at $t$, among those who have not yet adopted in the same time, $\frac{f(t)}{1-F(t)}$, is defined linearly as formula (1):

$$
\frac{f(t)}{1-F(t)}=p+q \cdot F(t)
$$

where $p$ is the innovation coefficient and $q$ is the imitation coefficient. Being $p, q \in(0,1)$ then $p<q$ and $(p+q)<1$.

When these parameters are quantified, previous evidence tells us that $p$ is often less than 0.1 and $q$ is typical range between 0.3 and 0.5 (Orbach, 2016), although, these values depend on are product specific (Sultan et al., 1990, as cited by Arellano \& Alonso, 2015).

The estimation from the initial equation proposed by the Bass Model (1) can be made by using the estimation of its solution expressed as an equation in differences of the total sales at time $t, S(t)$, so that $S(t)=m \cdot \frac{d F(t)}{d T}$, being $m$ the maximum number of people who can potentially adopt:

$$
\begin{aligned}
& \frac{d F(t)}{d t}=p \cdot m+(q-p) \cdot F(t-1)- \\
& -\frac{q}{m} \cdot F(t-1)^{2}
\end{aligned}
$$

The solution for $f(t)$ (3) has been reached by solving the formula in differences (2):

$$
f(t)=\frac{\left(\frac{p+q}{p}\right)^{2} \cdot e^{-(p+q) t}}{\left[1+\frac{q}{p} \cdot e^{-(p+q) t}\right]^{2}}
$$

The estimation of this solution (3) allows us to obtain directly the parameters $p, q$ and $m$, from which $f(t)$ can be represented and draw the density function previously introduced by the Bass Model.

Kijek and Kijek (2010) put forward four proposals to estimate the Bass Model. We follow their proposal using non-linear methods, solving the inconsistent estimation that might be achieved by the MCO estimation method.

\subsection{Machine-learning Algorithm to Group Tobacco Brands (Hartigan-Wong Algorithm, 1979)}

Once the adoption coefficients for the 138 brands of tobacco have been estimated, it is necessary to group them into similar sets. The purpose of this analysis is to identify heterogeneous behaviour that could be interpreted as different commercial profiles for each group of brands.

Therefore, we implement one of the most commonly used unsupervised machine-learning algorithms for partitioning a data set into k groups, k-means clustering (MacQueen et al., 1967). This algorithm allows the classification of brands into k different groups (pre-specified), where brands within the same cluster are as 
similar as possible and brands from different clusters are as dissimilar as possible. By analysing the centre of each cluster, we can find, in terms of innovation and imitation, which brand belongs to each cluster. In other words, the centre point of each cluster will give us information about diffusion behaviour for each brand.

We follow the Hartigan and Wong (1979) algorithm that defines the total within-cluster variation as the sum of squared Euclidean distances between states and the corresponding centroid:

$$
W\left(C_{k}\right)=\sum_{x_{i} \in C_{k}}\left(x_{i}-\mu_{k}\right)^{2}
$$

where $x_{i}$ is a data observation belonging to the cluster $C_{k}$ and $\mu_{k}$ is the mean value of the points assigned to the cluster $C_{k}$.

To select the optimal number of clusters to be generated, $k$, we compute k-means clustering using different values of clusters $k$ and we estimate the total within-cluster variation defined in function (5) and the silhouette graph proposed by Rousseeuw (1987) which is an evaluation of cluster validity.

$$
\sum_{k=1}^{K} W\left(C_{k}\right)=\sum_{k=1}^{K} \sum_{x_{i} \in C_{k}}\left(x_{i}-\mu_{k}\right)^{2}
$$

The location of a bend (knee) in the plot of the total within-cluster variation and the maximum value of the average silhouette width of each number of clusters $k$ is generally considered as an indicator of the appropriate number of clusters.

\section{Results}

In this section, we present the results in accordance with the described methodologies. We start by estimating the diffusion parameters for sales of the 138 best-seller Tobacco brands. Although all the estimated parameters have been included in the Appendix, Tab. A1 summarizes the results obtained. The parameters satisfy in terms of means the restrictions imposed within the model. In addition, the innovation coefficient $(p)$ is very low, the imitation coefficient (q) being substantially greater than this.

The results show that the advertising, promotion and sponsorship limitations introduced by law 28/2005 negates the importance of innovation in the diffusion process. Specifically, the law has lead to very low innovation parameters meaning that direct marketing actions are irrelevant in the diffusion process after the introduction of the ban. Moreover, the diffusion process in this market is slow during the period analysed, which is signalled by the low (p) value. However, the high (q) value reveals that imitation and recommendation is the coefficient leading the diffusion process during the period under consideration. This fact reveals that brands are dependent on the imitation factor and therefore, the degree of adoption is low in this market due to the dependence to the $(q)$ parameter.

In addition, it is of interest to discover whether the values of $(p)$ and $(q)$ are homogeneous or, by contrast, if they reveal heterogeneous patterns among different brands. Continuing this process, cluster analysis is implemented in order to identify different patterns in the diffusion process among brands of cigarettes.

First, it is necessary to perform an analysis of the optimal numbers of groups (clusters) into which brands will be divided. Fig. 3 shows the total within-cluster variation and the average silhouette width of each number of clusters $k$. The point at which a bend (knee) appears and the maximum average silhouette is considered the optimal cluster number to divide the data set into (cigarette brands). In our case, it seems to be located when we divide the set of tobacco brands into 3 groups.

Second, once we know the number of clusters in which we have to divide the 138 brands of cigarettes, we compute the clustering algorithm to uncover information about the groups created. In addition, as a measure of

Tab. 1: Descriptive statistics of the estimated parameters

\begin{tabular}{c|c|c|c|c|c} 
Coefficient & Obs & Mean & Std. dev. & Min & Max \\
\hline$p$ & 138 & 0.000035 & 0.0000814 & $3.97 \mathrm{e}-11$ & 0.000541 \\
\hline$q$ & 138 & 0.012342 & 0.0258662 & $4.52 \mathrm{e}-07$ & 0.160786 \\
\hline
\end{tabular}




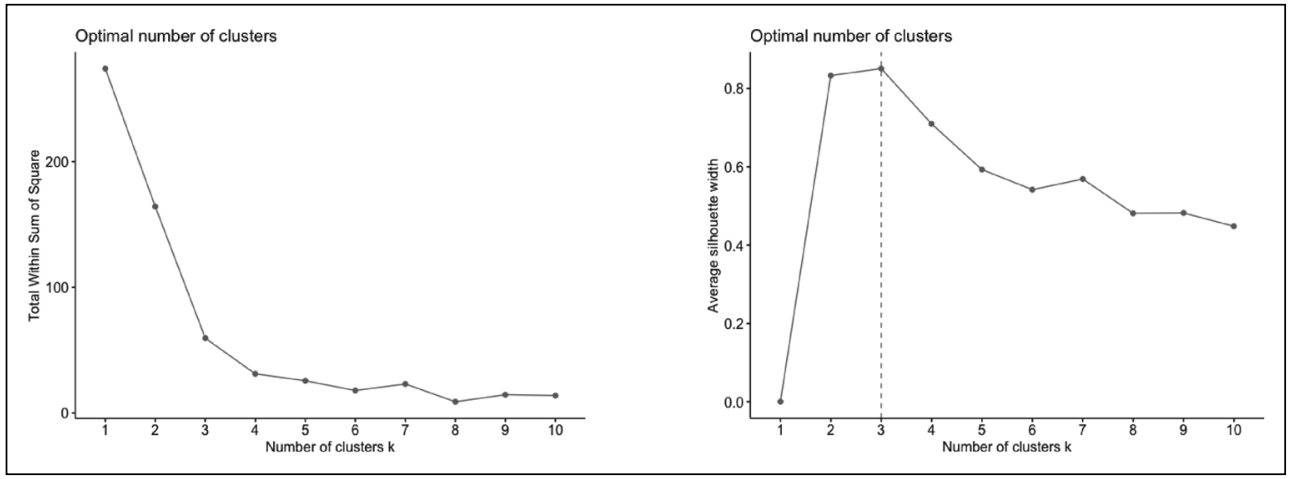

Source: own
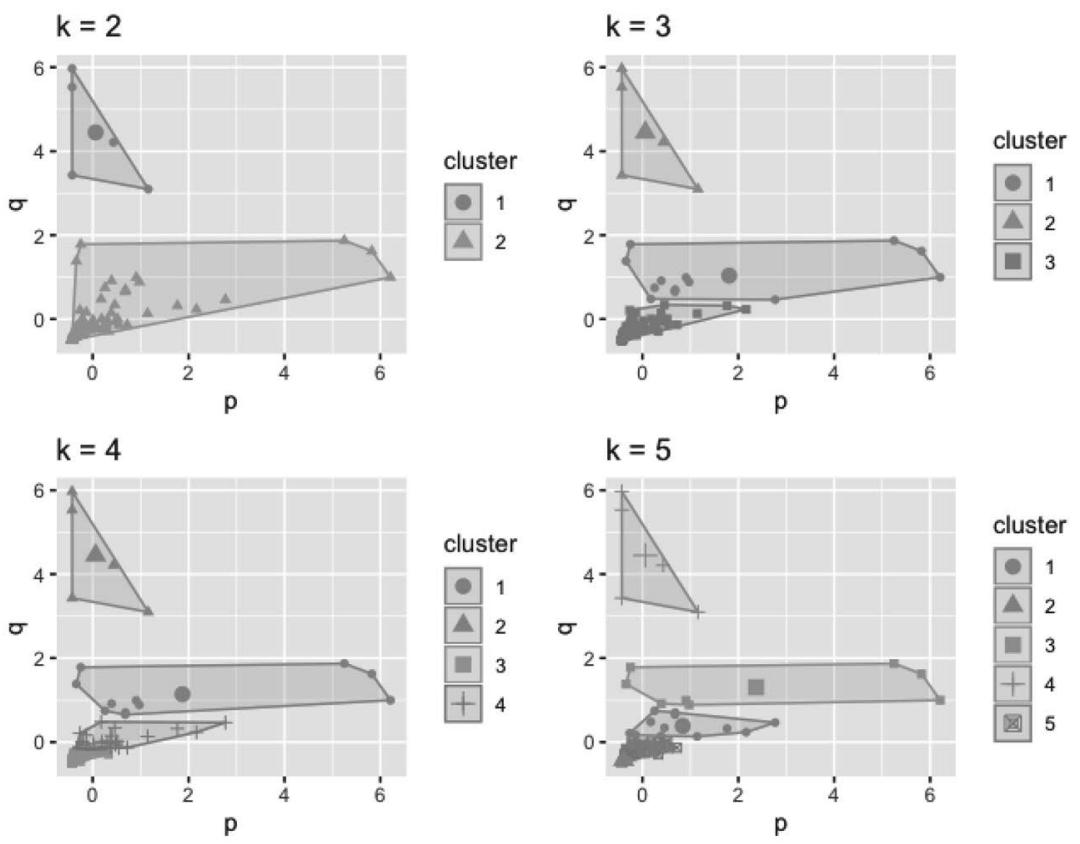

Source: own

robustness, we previously performed a visual analysis of the different clusters that would be created by dividing the sample into 2, 3, 4 and 5 groups. As can be seen in Fig. 4, when the number of groups is increased, the division is carried out according to the $y$-axis, $(q)$, which represents the imitation coefficient. 


\section{Marketing and Trade}

Our results reveal that the law $28 / 2005$ has generated a homogenization in the diffusion process when it is analysed by the innovation parameter. On the contrary, significant differences exist between different groups of brands due to the imitation coefficient.

In order to comment in depth on the results, we will focus on the analysis of the three groups into the 138 brands of cigarettes considered. Fig. 5 shows the graphical representation of the three groups and Tab. 2 shows the coefficients of innovation and imitation of the centroids of each group. The centroid is the middle of a cluster or group. A centroid is a vector that contains one number for each variable, where each number is the mean of a variable for the observations in that cluster. We can observe that different brands of cigarette are distributed mainly into three clusters according to the values of the diffusion coefficients.

\section{Fig. 5: K-means cluster analysis with three groups}

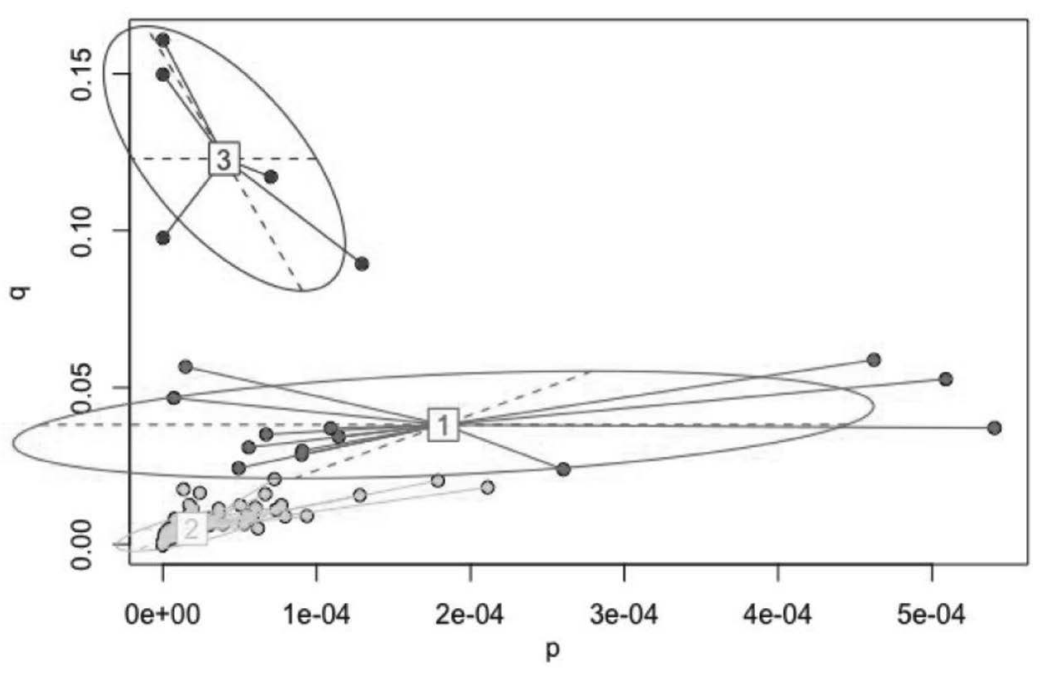

Source: own

\section{Centroid coefficients of each cluster}

\begin{tabular}{c|c|c} 
Cluster & $\mathbf{p}$ & $\mathbf{q}$ \\
\hline 1 & $1.82 \mathrm{e}-04$ & 0.038 \\
\hline 2 & $1.88 \mathrm{e}-05$ & 0.005 \\
\hline 3 & $3.99 \mathrm{e}-05$ & 0.123 \\
\hline
\end{tabular}

Source: own

As can be seen, cluster 1 , whose centroid is represented in red, is located in the middle of the other two clusters. It contains 13 brands of cigarettes, $9.42 \%$ of the total. Its centres are $p=1.823 e-04$ and $q=0.038$, representing the average of the imitation coefficient. Cluster 2, represented in green, is located in the bottom of the graph, and it contains the majority of the brands of cigarettes. Specifically, that group contains 120 brands of cigarettes, that 
is $86.96 \%$ of brands of cigarettes, with the lowest $(q)$ value $(q=0.0049)$. The lower value of $(q)$ in cluster 2 is reveals the slow expansion process of brands located here, indicating the maturity of these brands and, consequently, the maturity of the Spanish tobacco market. Finally, cluster 3 is represented in blue and, situated in the upper part of the graph, contains the least number of brands (only 5 brands are grouped in it, $3.62 \%$ of the total). This group presents the highest imitation coefficient (q value), meaning that an expansion process is taking place via imitation for these brands compared to those brands located in cluster 1 and 2 with a lower coefficient (q).

\section{Discussion}

In view of the results, we confirm that the innovation coefficient is irrelevant in the diffusion process and, in addition, it does not allow discrimination between brands. In other words, the marketing restrictions introduced by the $28 / 2005$ law generated a scenario in which there are no differences between brands in terms of innovation, meaning direct marketing strategies have only a residual effect on the diffusion process. However, brands are able to scale position by promoting imitations, since the (q) parameter is able to introduce heterogeneity in the diffusion process.

Consequently, the authors answer the research question and stated hypotheses:

$R Q$ : Can companies use marketing strategies to create advantages and scale positions in sales leadership after restrictive laws are introduced?

The answer is conditioned to the kind of marketing strategy since, because of the $28 / 2005$ law, the diffusion of tobacco based on innovation is homogeneous between brands, as confirmed by the results indicated by the innovation parameter. Consequently, if we are thinking about direct marketing actions, the answer to our research question is negative. However, brands can consider other marketing actions that introduce heterogeneity between them, such as the promotion of imitation in scaling position.

H1: Companies have options to implement direct marketing strategies that allow them to scale positions in sales leadership after the introduction of restrictive demand laws.

Rejected. As shown by the results, the diffusion of brands is homogeneous in terms of innovations. The significance of this is that companies are not able to differentiate themselves from the competition by implementing strategies aimed at diffusing their brands through innovations. Consequently, direct marketing strategies are not useful in discriminating between brands in these circumstances.

H2: The hierarchy in the market is consolidated and perpetuated once the market is regulated because of the inability of companies to use promotion and advertising to create advantages.

Accepted. Only the imitation coefficient in the diffusion process is considered as a discriminatory element between brands, indicating that it is only recommendation that leads to heterogeneity in brand adoption.

H3: In general, brands are not able to use marketing strategies to position themselves as leaders in the tobacco market.

Rejected. Direct marketing actions are not useful, but imitation shows heterogeneity among brands. Therefore, we confirm that marketing actions based on imitation are an alternative route to scale positions in the market.

The findings found in this article seem consistent with what is specified in the introduction section about previous literature. On the one hand, marketing-ban policies in a country appear to have a homogeneous effect on the marketing of regulated goods (in this case, tobacco products). In addition, the results show how anti-smoking laws reduce exposure to marketing influences, reducing product awareness and limiting the innovation coefficient in their diffusion. Finally, as established in the previous literature, this lower level of product knowledge seems to generate market concentration.

\section{Conclusions}

This article reviews marketing strategies in a regulated market by using the Bass Model to discriminate between imitation and innovation parameters being the factors responsible for allowing companies to lead the market.

This article is in line with other research using the diffusion process of products of a different nature, in order to distinguish between the two possible mechanisms leading the process: an external one - the innovation coefficient, and the internal mechanisms, based on relations with previous adopters. 
The scientific literature analysing the diffusion process does not consider some external effects that can enter in the diffusion process, such as governmental policies, as is the case of a regulated market where restrictivedemand laws are being implemented. The principal consequences of these laws are the limitation of the implementation of direct marketing strategies. This is the case of Spain, our market of analysis, where the 28/2005 law limited direct marketing actions prohibiting promotion and publicity outside of tobacco selling establishments.

Consequently, the aim of our research is to find the mechanism leading the diffusion process in order to identify the parameter that introduces heterogeneity among tobacco brands. That heterogeneity will reveal the possibilities of implementing marketing actions to scale position in the market.

As a conclusion, the most relevant finding of this research is that the innovation coefficients for the 138 tobacco brands are very low which may reflect, in general, that external effects are not relevant in the diffusion process of tobacco brands. This result shows the effectiveness of law 28/2005: differentiation among groups is only evident by use of the imitation coefficient, the innovation parameter being small and similar between brands. These results guarantee the objective of converting cigarettes into a less attractive and accessible product.

Summarizing, our empirical analysis reveals that the innovation coefficient is not a discriminating element in the process of brand diffusion. However, there are substantial differences in the imitation coefficient that discriminates brands. In addition, the tobacco market $(86.96 \%$ of the sample) is a mature market where the prohibitions implemented by law 28/2005 has meant that direct marketing actions have no effect in the diffusion process and only marketing actions focused on promoting imitation (social media and influencers market) can allow companies to position their brands.

Since brands can only be distinguished by the imitation coefficient, it seems that their position prior to the limitation of mass media advertising can be perpetuated over time. This may be one of the reasons explaining that, according to data from the Trade of Tobacco Commission, the big-four manufacturers control the $95 \%$ of the market (Philips Morris International, Imperial Tobacco, Japan Tobacco
International and British American Tobacco. The market share of each company is around $30 \%$ in the case of Philip Morris and Imperial Tobacco; and $25 \%$ and $10 \%$ in the case of Japan Tobacco International and British American Tobacco, respectively). In addition, the market shares of each of these manufacturers have remained stable in the 2005-2018 period, the period of our analysis.

The results obtained are instructive for governments since restrictions on the marketing of tobacco products seem to concentrate the process of diffusion of these products with an impact on public health. Regarding recommendations, these can be addressed to both governments and tobacco manufacturers. It is advisable for governments to limit the marketing of products that are harmful to health since these bans prevent the diffusion of those products from being driven by innovation. Furthermore, tobacco manufacturers should consider that only the word-of-mouth effect of the recommendation will lead to the improvement of the diffusion of tobacco products. Along these lines, it seems reasonable to indicate to tobacco manufacturers that campaigns should be aimed at the diffusion of the product by focusing on increasing the number of recommendations among consumers. The main theoretical implication is that, in line with previous literature, the prohibition of marketing activities in the tobacco sector causes homogenization. The contribution of this article to the literature is that, although the regulation of marketing in tobacco products causes homogenization, it seems that, because of customer recommendation, companies can continue to position themselves favourably in the market.

The tobacco monopoly retail network has enabled the Spanish government to influence the national market in the terms of the big four cigarette companies. This regime of restrictive policies appears to have been effective in the implementation of measures making tobacco products less attractive. In addition, given that the Canary Islands is not currently subject to the tobacco monopoly retail network, and supposing the government aims to make tobacco products less attractive and accessible on that territory, bringing it into line with the rest of Spain by submitting it to the same regime is advisable.

The main limitation of this research is that this study focuses on analysing only the 
tobacco market and attempting to generalize to other regulated markets. Although the results are considered an important advance, it is not known if this is a particular feature of the sector under study or whether the results can be extrapolated. Therefore, the authors recommend replicating this study in other sectors to compare results. Furthermore, as indicated in the paper, cigarettes currently account for around $85 \%$ of the tobacco market in Spain. For this reason, it is important to bear in mind that, although homogeneous behaviour has been observed in the diffusion of the different cigarette brands, this may not be the case for alternative products. Furthermore, official cigarette sales have been used, and these are conditioned by sales to tourists and the cross-border effect. A recent study indicates that there are distortions in official cigarette sales in the border areas with France and Gibraltar (Almeida et al., 2020a, 2020b). Another important point is that the sample used contains sales data during the Great Recession. A recent study indicates that in Spain the effect of economic cycles on tobacco consumption is asymmetric, with a decrease in legal sales of cigarettes in recession phases (Martín Álvarez et al., 2020b). Finally, when using total sales data, it is not possible to distinguish the diffusion of tobacco products between the different age groups.

There are several lines of future research. An analysis of the spread of rolling tobacco products would be useful to understand whether the impact of the ban on marketing actions has had an equal impact on all products. In addition, the irruption in the market for heated tobacco, accompanied by electronic devices that heat tobacco, means it is important to know whether the prohibitions on tobacco marketing have been respected in the marketing of these products. For instance, in Spain, since 2016, IQOS has been marketed, a device for heating tobacco (Heets) designed by the tobacco company Philip Morris International. There are many criticisms that this company has marketed the product as an electronic device, rather than as a tobacco product. Heets diffusion analysis may help to understand whether this hypothesis really holds.

\section{References}

Almeida, A., Golpe, A. A., \& Martín Álvarez, J. M. (2020a). A spatial analysis of the Spanish tobacco consumption distribution: Are there any consumption clusters? Public Health, 186, 28-30. https://doi.org/10.1016/j. puhe.2020.06.040

Almeida, A., Golpe, A. A., Iglesias, J., \& Martín Álvarez, J. M. (2020b). The price elasticity of cigarettes: new evidence from Spanish regions, 2002-2016. Nicotine \& Tobacco Research, 23(1), 48-56. https://doi. org/10.1093/ntr/ntaa131

Alonso, J., \& Arellano, A. (2015). Heterogeneidad y difusión de la economía digital: el caso español (Working paper $\mathrm{N}^{\circ}$ 15/28). Bilbao: BBVABank, Economic Research Department. Retrieved from https://EconPapers. repec.org/RePEc:bbv:wpaper:1528

Ayaviri Nina, V. D., Quispe Fernández, G. M., \& Sánchez Cuesta, P. (2017). Estimación de la demanda del turismo en la Comunidad Andina de Naciones. Revista Espacios, 38(31), 51-69. Retrieved from https://www. revistaespacios.com/a17v38n31/a17v38n31p24.pdf

Bass, F. M. (1969). A New Product Growth Model for Consumer Durables. In Mathematical Models in Marketing. Lecture Notes in Economics and Mathematical Systems (Operations Research) (Vol. 132, pp. 351-353). Berlin, Heidelberg: Springer. https://doi. org/10.1007/978-3-642-51565-1_107

Bass, F. M. (1980). The Relationship between Diffusion Rates, Experience Curves, and Demand Elasticities for Consumer Durable Technological Innovations. The Journal of Business, 53(3), S51-67. Retrieved from https://EconPapers.repec.org/ RePEc:ucp:jnlbus:v:53:y:1980:i:3:p:s51-67

Bass, F. M., \& Bultez, A. V. (1982). Technical Note - A Note on Optimal Strategic Pricing of Technological Innovations. Marketing Science, 1(4), 371-378. https://doi.org/10.1287/mksc.1.4.371

Bayus, B. L. (1992). Have diffusion rates been accelerating over time? Marketing Letters, 3, 215-226. https://doi.org/10.1007/ bf00994130

CDC. (2004). The Health Consequences of Smoking (2004 Surgeon General's Report). Atlanta, GA: Center for Disease Control and Prevention. Office of Smoking and Health. Retrieved from https://www.cdc.gov/tobacco/ data_statistics/sgr/2004/

Cho, Y. J., Thrasher, J., Cummings, M., Yong, H. H., Hitchman, S. C., McNeill, A., Fong, G. T., Hammond, D., Hardin, J., Li, L., \& Lindblom, E. N. (2020). Cross-country comparison 
of cigarette and vaping product marketing exposure and use: Findings from 2016 ITC Four Country Smoking and Vaping Survey. Tobacco Control, 29(3), 295-304. https://doi. org/10.1136/tobaccocontrol-2018-054650

Contreary, K. A., Chattopadhyay, S. K., Hopkins, D. P., Chaloupka, F. J., Forster, J. L., Grimshaw V., \& Fielding, J. E. (2015). Economic Impact of Tobacco Price Increases Through Taxation: A Community Guide Systematic Review. American Journal of Preventive Medicine, 49(5), 800-808. https:// doi.org/10.1016/j.amepre.2015.04.026

Craig, L. V., Yoshimi, I., Fong, G. T., Meng, G., Yan, M., Mochizuki, Y., Tabuchi, T., Trasher, J. F., Su, S. S., Quah, A. C. K., Ouimet, J., Sansone, G., \& Chung-Hall, J. (2020). Awareness of Marketing of Heated Tobacco Products and Cigarettes and Support for Tobacco Marketing Restrictions in Japan: Findings from the 2018 International Tobacco Control (ITC) Japan Survey. International Journal of Environmental Research and Public Health, 17(22), 8418. https://doi.org/10.3390/ ijerph17228418

Dolan, R. J., \& Jeuland, A. P. (1981). Experience Curves and Dynamic Demand Models: Implications for Optimal Pricing Strategies. Journal of Marketing, 45(1), 52-62. https://doi.org/10.1177/002224298104500106

El-Toukhy, S., Choi, K., Hitchman, S. C., Bansal-Travers, M., Thrasher, J. F., Yong, H. H., O'Connor, R., \& Shang, C. (2018). Banning tobacco price promotions, smokingrelated beliefs and behaviour: findings from the International Tobacco Control Four Country (ITC 4C) Survey. Tobacco Control, 27(3), 310-318. https://doi.org/10.1136/ tobaccocontrol-2017-053648

Escario, J. J., \& Molina, J. A. (2004). Modeling the optimal fiscal policy on tobacco consumption. Journal of Policy Modeling, 26(1), 81-93. https://doi.org/10.1016/j. jpolmod.2003.11.003

Fernández, M. F., Artacho-Cordón, F., Freire, C., Pérez-Lobato, R., Calvente, I., Ramos, R., \& Olea, N. (2015). Trends in childrens exposure to second-hand smoke in the INMA-Granada cohort: An evaluation of the Spanish anti-smoking law. Environmental Research, 138, 461-468. https://doi. org/10.1016/j.envres.2015.03.002

Galán, I., Mata, N., Estrada, C., DíezGañan, L., Velázquez, L., Zorrilla, B., \& Ortiz,
H. (2007). Impact of the "Tobacco control law" on exposure to environmental tobacco smoke in Spain. BMC Public Health, 7, 224. https://doi. org/10.1186/1471-2458-7-224

Gnann, T., Stephens, T. S., Lin, Z., Plötz, P., Liu, C., \& Brokate, J. (2018). What drives the market for plug-in electric vehicles? A review of international PEV market diffusion models. Renewable and Sustainable Energy Reviews, 93, 158-164. https://doi.org/10.1016/j. rser.2018.03.055

Harris, F., MacKintosh, A. M., Anderson, S., Hastings, G., Borland, R., Fong, G. T., Hammond, D., \& Cummings, K. M. (2006). Effects of the 2003 advertising/promotion ban in the United Kingdom on awareness of tobacco marketing: findings from the International Tobacco Control (ITC) Four Country Survey. Tobacco Control, 15(suppl 3), iii26-iii33. https:// doi.org/10.1136/tc.2005.013110

Hartigan, J. A., \& Wong, M. A. (1979). Algorithm AS 136: A K-Means Clustering Algorithm. Applied Statistics, 28(1), 100-108. https://doi.org/10.2307/2346830

Henriksen, L. (2012). Comprehensive tobacco marketing restrictions: promotion, packaging, price and place. Tobacco Control, 21(2), 147-153. https://doi.org/10.1136/ tobaccocontrol-2011-050416

Jiang, Y. P. (2017). Study on the Diffusion of the Instant Messaging Market Based on the Modified Bass Model. In 2017 International Conference on Economics and Management Engineering (ICEME 2017). Wuhan, China. https://doi.org/10.12783/dtem/ iceme2017/11764

Jiménez-Ruiz, C. A., Miranda, J. A., Hurt, R. D., Pinedo, A. R., Reina, S. S., \& Valero, F. C. (2008). Study of the impact of laws regulating tobacco consumption on the prevalence of passive smoking in Spain. European Journal of Public Health, 18(6), 622-625. https://doi. org/10.1093/eurpub/ckn066

Joga Rao, G., Shrivastava S. K., \& Gouse Baig, M. (2016). Diffusion Modeling and Implementation of Renewable Energy Technologies in India. International Advanced Research Journal in Science, Engineering and Technology ISO 3297:2007 Certified, 3(8), 106-119.

Kasza, K. A., Hyland, A. J., Brown, A., Siahpush, M., Yong, H. H., McNeill, A. D., Li, L., \& Cummings, K. M. (2011). The Effectiveness of Tobacco Marketing Regulations on Reducing 
Smokers' Exposure to Advertising and Promotion: Findings from the International Tobacco Control (ITC) Four Country Survey. International Journal of Environmental Research and Public Health, 8(2), 321-340. https://doi.org/10.3390/ijerph8020321

Kijek, A., \& Kijek, T. (2010). Modelling of innovation diffusion. Operations Research and Decisions, 20(3), 53-68. Retrieved from http://www.ord.pwr.wroc.pl/index.php?s=archive

Lavasani, M., Jin, X., \& Du, Y. (2016). Market Penetration Model for Autonomous Vehicles on the Basis of Earlier Technology Adoption Experience. Transportation Research Record: Journal of the Transportation Research Board, 2597(1), 67-74. https://doi.org/10.3141/2597-09

Long, Z., Chang, J., \& Chen, Z. (2016). Effects of Incentives to the Promotion of New Energy Vehicles-Based on the Empirical Analysis of Modified Bass Model. Science and Technology Management Research, 36(4), 138-144. Retrieved from http://en.cnki.com.cn/ Article_en/CJFDTotal-KJGL201604026.htm

López-Arrieta, J. M., \& Sanz, F. J. (2001). Nicotine for Alzheimer's disease. Cochrane Database of Systematic Reviews, 2. https://doi. org/10.1002/14651858.cd001749

MacQueen, J. E. (1967). Some methods for classification and analysis of multivariate observations. In Proceedings of the Fifth Berkeley symposium on mathematical statistics and probability (Vol. 5.1, pp. 281-297). https:// projecteuclid.org/euclid.bsmsp/1200512992

Mahajan, V., Muller, E., \& Bass, F. M. (1995). Diffusion of New Products: Empirical Generalizations and Managerial Uses. Marketing Science, 14(3), G79-G88. https:// doi.org/10.1287/mksc.14.3.g79

Martín Álvarez, J. M., Golpe, A. A., Iglesias, J., \& Ingelmo, R. (2020a). Price and income elasticities of demand for cigarette consumption: what is the association of price and economic activity with cigarette consumption in Spain from 1957 to 2016? Public Health, 185, 275-282. https://doi.org/10.1016/j.puhe.2020.05.059

Martín Álvarez, J. M., Almeida, A., Galiano, A., \& Golpe, A. A. (2020b). Asymmetric behavior of tobacco consumption in Spain across the business cycle: a long-term regional analysis. International Journal of Health Economics and Management, 20(4), 391-421. https://doi. org/10.1007/s10754-020-09286-y

Mersky, A. C., Sprei, F., Samaras, C., \& Qian, Z. (2016). Effectiveness of incentives on electric vehicle adoption in Norway. Transportation Research Part D: Transport and Environment, 46, 56-68. https://doi. org/10.1016/j.trd.2016.03.011

Mirza, M. (2019). Advertising Restrictions and Market Concentration in the Cigarette Industry: ACross-Country Analysis. International Journal of Environmental Research and Public Health, 16(18), 3364. https://doi.org/10.3390/ ijerph16183364

Moodie, C., MacKintosh, A. M., Brown, A., \& Hastings, G. B. (2008). Tobacco marketing awareness on youth smoking susceptibility and perceived prevalence before and after an advertising ban. European Journal of Public Health, 18(5), 484-490. https://doi.org/10.1093/ eurpub/ckn016

Orbach, Y. (2016). Parametric analysis of the Bass Model. Innovative Marketing, 12(1), 29-40. https://doi.org/10.21511/im.12(1).2016.03

Pinilla, J., \& Abásolo, I. (2017). The effect of policies regulating tobacco consumption on smoking initiation and cessation in Spain: is it equal across socioeconomic groups? Tobacco Induced Diseases, 15(1), 8. https://doi.org/10.1186/s12971-016-0109-4

Pinilla, J., López-Valcárcel, B. G., \& Negrín, M. A. (2019). Impact of the Spanish smoke-free laws on cigarette sales, 2000-2015: Partial bans on smoking in public places failed and only a total tobacco ban worked. Health Economics, Policy and Law, 14(4), 536-552. https://doi. org/10.1017/s1744133118000270

Pons-Vigués, M., Rando-Matos, Y., Rodriguez-Blanco, T., Ballvé-Moreno, J. L., Ripoll, J., Llobera, J., Morán, J., López-Jiménez, T., Violán-Fors, C., \& Bolibar, B. (2019). Effect of the comprehensive smoke-free law on time trends in smoking behaviour in primary healthcare patients in Spain: A longitudinal observational study. BMJ Open, 9(3), e020120. https://doi.org/10.1136/bmjopen-2017-020120

Porath, D., \& Schaefer, C. (2014). Applying the Bass Model to pharmaceuticals in emerging markets. International Journal of Market Research, 56(4), 513-530. https://doi. org/10.2501/ijmr-2014-033

Ratcliff, R., Smith, P. L., Brown, S. D., \& McKoon, G. (2016). Diffusion Decision Model: Current Issues and History. Trends in Cognitive Sciences, 20(4), 260-281. https://doi. org/10.1016/j.tics.2016.01.007

Rousseeuw, P. J. (1987). Silhouettes: A graphical aid to the interpretation and validation 


\section{Marketing and Trade}

of cluster analysis. Journal of Computational and Applied Mathematics, 20, 53-65. https://doi.org/10.1016/0377-0427(87)90125-7

Ruiz, C. A., Miranda, J. A., Gómez, N. A., Costa-Miñana, J. S., Blasco, J. J., Manzano, J. R., \& de Lucas Ramos, P. (2014). Impact of Legislation on Passive Smoking in Spain. Respiration, 87(3), 190-195. https://doi. org/10.1159/000355083

Sierzchula, W., Bakker, S., Maat, K., \& van Wee, B. (2014). The influence of financial incentives and other socio-economic factors on electric vehicle adoption. Energy Policy, 68, 183194. https://doi.org/10.1016/j.enpol.2014.01.043

Song, S., Cho, N.-W., \& Kim, T. (2016). Success Factors of Game Products by Using a Diffusion Model and Cluster Analysis. Journal of Korean Institute of Industrial Engineers, 42(3), 222-230. https://doi.org/10.7232/ jkiie.2016.42.3.222
Turk, T., \& Trkman, P. (2012). Bass Model estimates for broadband diffusion in European countries. Technological Forecasting and Social Change, 79(1), 85-96. https://doi.org/10.1016/j. techfore.2011.06.010

Usha Rao, K., \& Kishore, V. V. (2010). A review of technology diffusion models with special reference to renewable energy technologies. Renewable and Sustainable Energy Reviews, 14(3), 1070-1078. https://doi. org/10.1016/j.rser.2009.11.007

Weissmann, V. (2008). Difusión de nuevas tecnologías y estimación de la demanda de nuevos productos: un análisis comparativo entre Argentina y EEUU. Palermo Business Review, 1, 5-17. Retrieved from https://www. palermo.edu/economicas/pdf_economicas/ business_paralela/review/1Business01.pdf

World Health Organization (WHO). (2003). WHO Framework Convention on Tobacco Control. http://www.who.int/fctc/text_download/en/ 
Tab. A1: Estimated Bass Model coefficients - Part 1

\begin{tabular}{|c|c|c|c|c|c|c|c|c|c|c|c|}
\hline Brand & $p$ & & $q$ & & $\mathrm{R}^{2}$ & Brand & $p$ & & $q$ & & $\mathbf{R}^{2}$ \\
\hline MARLBORO & $8.050 \mathrm{E}-07$ & $\star * \star$ & $2.465 \mathrm{E}-03$ & $* * *$ & 0.971 & EGALITE & $8.080 \mathrm{E}-07$ & & 4.794E-04 & & 0.845 \\
\hline FORTUNA & $1.390 \mathrm{E}-06$ & $* \star \star$ & $3.546 \mathrm{E}-03$ & $* * *$ & 0.965 & $\begin{array}{l}\text { CHESTERFIELD } \\
\text { SEMI-RIGIDO }\end{array}$ & $8.960 \mathrm{E}-07$ & & $9.708 \mathrm{E}-04$ & & 0.991 \\
\hline WINSTON & $1.940 \mathrm{E}-07$ & $* *$ & $6.847 \mathrm{E}-04$ & $* \star \star$ & 0.886 & KRUGER & $9.060 \mathrm{E}-05$ & $* \star *$ & $2.983 \mathrm{E}-02$ & $* \star \star$ & 0.955 \\
\hline CHESTERFIELD & $9.530 \mathrm{E}-07$ & $* * *$ & $2.476 \mathrm{E}-03$ & $* * *$ & 0.977 & KOOL & $9.930 \mathrm{E}-06$ & $* \star \star$ & $3.327 \mathrm{E}-03$ & $* \star *$ & 0.949 \\
\hline DUCADOS NEGRO & $1.640 \mathrm{E}-06$ & *** & $3.611 \mathrm{E}-03$ & $* * *$ & 0.982 & AMERICAN LEGEND & $1.960 \mathrm{E}-10$ & *** & $9.170 \mathrm{E}-07$ & & 0.801 \\
\hline CAMEL & $4.750 \mathrm{E}-07$ & $\star \star \star *$ & $1.255 \mathrm{E}-03$ & $* * *$ & 0.967 & MORE & $6.720 \mathrm{E}-06$ & 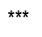 & $2.345 \mathrm{E}-03$ & 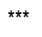 & 0.947 \\
\hline L\&M & $8.860 \mathrm{E}-07$ & $\star \star *$ & $1.964 \mathrm{E}-03$ & $* * *$ & 0.964 & PRINCE & $1.270 \mathrm{E}-05$ & $\star \star \star *$ & $4.014 \mathrm{E}-03$ & $\star \star \star *$ & 0.810 \\
\hline LUCKY STRIKE & $2.450 \mathrm{E}-07$ & $\star \star * *$ & $6.960 \mathrm{E}-04$ & $* * *$ & 0.943 & $\begin{array}{l}\text { MARLBORO CORE } \\
\text { FLAVOR }\end{array}$ & $1.340 \mathrm{E}-05$ & $\star \star \star *$ & $1.756 \mathrm{E}-02$ & & 0.324 \\
\hline DUCADOS RUBIO & $1.440 \mathrm{E}-06$ & $\star * *$ & $2.923 \mathrm{E}-03$ & $* * *$ & 0.807 & LIBERTE & $2.450 \mathrm{E}-10$ & $* * *$ & $1.010 \mathrm{E}-06$ & & 0.895 \\
\hline NOBEL & $1.030 \mathrm{E}-06$ & $\star * *$ & $2.151 \mathrm{E}-03$ & $* * *$ & 0.964 & PALACE & $3.630 \mathrm{E}-05$ & $* * *$ & $1.138 \mathrm{E}-02$ & $* * *$ & 0.885 \\
\hline PALL MALL & $1.390 \mathrm{E}-06$ & *** & $2.299 \mathrm{E}-03$ & $* * *$ & 0.754 & PIPER & $2.020 \mathrm{E}-05$ & $\star * *$ & $6.019 \mathrm{E}-03$ & $\star * \star$ & 0.949 \\
\hline JOHN PLAYER SP. & $3.320 \mathrm{E}-06$ & *** & $4.800 \mathrm{E}-03$ & $* * *$ & 0.885 & WINGS & $2.090 \mathrm{E}-05$ & *** & $6.615 \mathrm{E}-03$ & *** & 0.700 \\
\hline ELIXYR & $7.820 \mathrm{E}-06$ & $* * *$ & $8.191 \mathrm{E}-03$ & $* * *$ & 0.874 & MARLBORO WIDES & $5.580 \mathrm{E}-05$ & $* * *$ & $3.090 \mathrm{E}-02$ & $* * *$ & 0.966 \\
\hline GOLD COAST & 3.410E-06 & $* * *$ & 3.693E-03 & $* * *$ & 0.959 & DORCHESTER & $7.250 \mathrm{E}-05$ & $* * *$ & $2.080 \mathrm{E}-02$ & $* * *$ & 0.693 \\
\hline PHILIP MORRIS & $7.940 \mathrm{E}-07$ & * & 1.037E-03 & $* *$ & 0.721 & FINE 120 & $1.560 \mathrm{E}-06$ & & 7.587E-04 & & 0.889 \\
\hline CORONAS RUBIO & $4.940 \mathrm{E}-06$ & $* * *$ & $5.050 \mathrm{E}-03$ & $* * *$ & 0.915 & CRAVEN A & $6.450 \mathrm{E}-06$ & $* * *$ & $1.950 \mathrm{E}-03$ & $* * *$ & 0.972 \\
\hline LAMBERT \& BUTLER & $8.120 \mathrm{E}-06$ & $* * *$ & $7.632 \mathrm{E}-03$ & $* * *$ & 0.848 & $\mathrm{HB}$ & $2.200 \mathrm{E}-05$ & $* * *$ & $6.865 \mathrm{E}-03$ & $\star * \star$ & 0.835 \\
\hline FORTUNA RED LINE & $1.250 \mathrm{E}-06$ & $* * *$ & $1.680 \mathrm{E}-03$ & $* \star \star$ & 0.958 & KENSITAS CLUB & $5.020 \mathrm{E}-05$ & $* * *$ & $1.249 \mathrm{E}-02$ & $* * *$ & 0.836 \\
\hline $\mathrm{BN}$ & $4.060 \mathrm{E}-06$ & $* * *$ & 3.647E-03 & $* * \star$ & 0.987 & UN-X-2 & $3.650 \mathrm{E}-05$ & *** & $9.934 \mathrm{E}-03$ & $* * *$ & 0.913 \\
\hline BENSON \& HEDGES & $6.590 \mathrm{E}-06$ & $* * *$ & $5.421 \mathrm{E}-03$ & $* * *$ & 0.849 & $\begin{array}{l}\text { NATURAL } \\
\text { AMERICAN }\end{array}$ & $2.370 \mathrm{E}-10$ & $* * *$ & $8.300 \mathrm{E}-07$ & & 0.856 \\
\hline EXCITE & $1.720 \mathrm{E}-05$ & $* * \star$ & $1.260 \mathrm{E}-02$ & $* \star \star *$ & 0.873 & EL KAISER & $2.880 \mathrm{E}-05$ & $* * *$ & $8.207 \mathrm{E}-03$ & $* * \star$ & 0.952 \\
\hline WEST & $5.720 \mathrm{E}-06$ & *** & $4.565 \mathrm{E}-03$ & $* \star \star$ & 0.726 & CAMEL SHORTS & 4.100E-06 & * & $1.785 \mathrm{E}-03$ & * & 0.952 \\
\hline SUPERKINGS & $8.440 \mathrm{E}-06$ & $* \star \star$ & $6.282 \mathrm{E}-03$ & 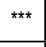 & 0.868 & LATINO & $1.294 \mathrm{E}-04$ & *** & $8.933 \mathrm{E}-02$ & *** & 0.447 \\
\hline GAULOISES RUBIO & $1.350 \mathrm{E}-06$ & $* \star * *$ & 1.247E-03 & $* \star * *$ & 0.856 & H.B. & $2.020 \mathrm{E}-06$ & & $1.091 \mathrm{E}-03$ & & 0.814 \\
\hline POPULAR & $6.780 \mathrm{E}-06$ & *** & 4.969E-03 & $* * \star$ & 0.972 & RECORD & $6.660 \mathrm{E}-05$ & * & $1.602 \mathrm{E}-02$ & ** & 0.595 \\
\hline MARK 1 & $1.300 \mathrm{E}-10$ & $* * \star$ & $1.310 \mathrm{E}-06$ & & 0.893 & POPULAR RUBIO & 1.143E-04 & $* \star *$ & $3.432 \mathrm{E}-02$ & $* \star *$ & 0.956 \\
\hline MAYFAIR & $2.880 \mathrm{E}-06$ & *** & 2.287E-03 & $\star * * *$ & 0.762 & MECANICOS & $2.370 \mathrm{E}-05$ & *** & $5.696 \mathrm{E}-03$ & $\star \star \star *$ & 0.845 \\
\hline HABANOS & $4.570 \mathrm{E}-06$ & $* * *$ & $3.752 \mathrm{E}-03$ & $* * *$ & 0.989 & DIANA & $3.310 \mathrm{E}-05$ & $* * *$ & $7.673 \mathrm{E}-03$ & $* * *$ & 0.929 \\
\hline ROTHMANS & $3.970 \mathrm{E}-11$ & $* * *$ & $4.520 \mathrm{E}-07$ & & 0.315 & CAPAVANA & $9.020 \mathrm{E}-05$ & *** & $2.856 \mathrm{E}-02$ & $\star * *$ & 0.792 \\
\hline GOLDEN AMERICAN & $6.180 \mathrm{E}-06$ & *** & $4.542 \mathrm{E}-03$ & $* * *$ & 0.909 & VICEROY & $3.060 \mathrm{E}-05$ & *** & $6.718 \mathrm{E}-03$ & $\star \star \star *$ & 0.945 \\
\hline NEXT & $1.140 \mathrm{E}-05$ & $\star * *$ & 8.043E-03 & $* * *$ & 0.446 & ESSE & $1.510 \mathrm{E}-06$ & & $6.265 \mathrm{E}-04$ & & 0.833 \\
\hline SILK CUT & $3.240 \mathrm{E}-06$ & $* * *$ & $2.452 \mathrm{E}-03$ & $* * *$ & 0.859 & KENT & $3.890 \mathrm{E}-09$ & & $7.330 \mathrm{E}-06$ & & 0.870 \\
\hline AUSTIN & $1.400 \mathrm{E}-09$ & & $6.770 \mathrm{E}-06$ & & 0.681 & " $46 "$ & $3.110 \mathrm{E}-05$ & *** & $7.290 \mathrm{E}-03$ & $* * *$ & 0.969 \\
\hline $\mathrm{R} 1$ & $4.120 \mathrm{E}-11$ & $* * *$ & $4.520 \mathrm{E}-07$ & & 0.976 & BROOKFIELD & $2.990 \mathrm{E}-05$ & $* * *$ & $5.982 \mathrm{E}-03$ & $* * *$ & 0.744 \\
\hline AMERICAN JEAN'S & $2.400 \mathrm{E}-05$ & $* * \star$ & $1.640 \mathrm{E}-02$ & $\star * \star *$ & 0.764 & LOLA & $6.020 \mathrm{E}-05$ & *** & 1.174E-02 & *** & 0.947 \\
\hline $\begin{array}{l}\text { PETER } \\
\text { STUYVESANT }\end{array}$ & $5.130 \mathrm{E}-06$ & $\star \star \star *$ & $3.522 \mathrm{E}-03$ & $\star \star \star *$ & 0.935 & $\begin{array}{l}\text { LUCKY STRIKE SIN } \\
\text { FILTRO }\end{array}$ & $2.120 \mathrm{E}-05$ & $\star \star \star$ & $7.352 \mathrm{E}-03$ & $\star \star \star *$ & 0.944 \\
\hline
\end{tabular}




\section{Tab. A1: Estimated Bass Model coefficients - Part 2}

\begin{tabular}{|c|c|c|c|c|c|c|c|c|c|c|c|}
\hline Brand & $p$ & & $q$ & & $\mathbf{R}^{2}$ & Brand & $p$ & & $q$ & & $\mathbf{R}^{2}$ \\
\hline WINFIELD & 4.730E-06 & $* \star * *$ & $3.237 \mathrm{E}-03$ & *** & 0.918 & ROMEO Y JULIETA & $2.180 \mathrm{E}-05$ & 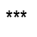 & $3.899 \mathrm{E}-03$ & 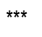 & 0.952 \\
\hline BROOKLYN & $7.950 \mathrm{E}-11$ & $* * *$ & $7.530 \mathrm{E}-07$ & & 0.275 & GOLD LEAF & $7.710 \mathrm{E}-05$ & 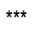 & $1.252 \mathrm{E}-02$ & $\star \star \star *$ & 0.945 \\
\hline CELTAS & $1.930 \mathrm{E}-05$ & $* \star *$ & 1.135E-02 & *** & 0.971 & ALONSO & $3.640 \mathrm{E}-10$ & *** & $1.010 \mathrm{E}-06$ & & 0.705 \\
\hline NEWS & $1.790 \mathrm{E}-06$ & ${ }^{* *}$ & $1.326 \mathrm{E}-03$ & $* * *$ & 0.736 & $\begin{array}{l}\text { CK CANARY } \\
\text { KINGDOM }\end{array}$ & $1.650 \mathrm{E}-05$ & $\star \star \star *$ & $2.953 \mathrm{E}-03$ & *** & 0.522 \\
\hline RICHMOND & $1.090 \mathrm{E}-10$ & $* * *$ & $8.470 \mathrm{E}-07$ & & 0.672 & IBIZA & $1.470 \mathrm{E}-05$ & & $5.665 \mathrm{E}-02$ & & 0.173 \\
\hline KARELIA & 1.180E-09 & & $5.200 \mathrm{E}-06$ & & 0.762 & MS & $5.480 \mathrm{E}-05$ & ** & $9.380 \mathrm{E}-03$ & $* * *$ & 0.883 \\
\hline CORONAS NEGRO & $8.850 \mathrm{E}-06$ & $* * *$ & $5.190 \mathrm{E}-03$ & $* * *$ & 0.97 & MATRIX & $7.360 \mathrm{E}-05$ & ** & $1.110 \mathrm{E}-02$ & $* * *$ & 0.552 \\
\hline DENIM & $1.490 \mathrm{E}-05$ & $* * *$ & 8.463E-03 & $* * *$ & 0.738 & TRUCCO & $1.200 \mathrm{E}-05$ & $* * *$ & $4.081 \mathrm{E}-03$ & $* *$ & 0.963 \\
\hline REGAL & $1.360 \mathrm{E}-05$ & $* * *$ & 7.479E-03 & $* * *$ & 0.847 & MAYA & $1.030 \mathrm{E}-05$ & * & $2.403 \mathrm{E}-03$ & * & 0.817 \\
\hline DESERT GOLD & $5.250 \mathrm{E}-06$ & $* * *$ & 3.353E-03 & $* * *$ & 0.809 & LORD & 7.380E-05 & $\star *$ & $1.093 \mathrm{E}-02$ & $* * *$ & 0.79 \\
\hline VOGUE & $7.360 \mathrm{E}-10$ & & $3.870 \mathrm{E}-06$ & & 0.182 & DAVIDOFF & $1.310 \mathrm{E}-07$ & & $9.761 \mathrm{E}-02$ & & 0.335 \\
\hline BURTON & $5.330 \mathrm{E}-06$ & $* * *$ & 3.009E-03 & $* * *$ & 0.834 & JEAN & $1.281 \mathrm{E}-04$ & $* * *$ & $1.564 \mathrm{E}-02$ & $* * *$ & 0.901 \\
\hline OMÉ & $1.440 \mathrm{E}-10$ & $* * \star$ & $1.070 \mathrm{E}-06$ & & 0.698 & DAVIDOFF NEGRO & 4.623E-04 & & $5.886 \mathrm{E}-02$ & * & 0.913 \\
\hline SAX & $1.740 \mathrm{E}-05$ & $* * *$ & $9.990 \mathrm{E}-03$ & $* * *$ & 0.785 & KIM & $1.788 \mathrm{E}-04$ & $\star *$ & $2.032 \mathrm{E}-02$ & $* * *$ & 0.763 \\
\hline ROYALS & $8.940 \mathrm{E}-06$ & $* * \star$ & $4.712 \mathrm{E}-03$ & $* * *$ & 0.771 & CARTIER & $3.900 \mathrm{E}-05$ & & $6.379 \mathrm{E}-03$ & & 0.949 \\
\hline RONSON & $9.950 \mathrm{E}-06$ & $* * \star$ & $5.614 \mathrm{E}-03$ & $* * *$ & 0.743 & PRIVIUM & $5.840 \mathrm{E}-05$ & $* * *$ & $9.115 \mathrm{E}-03$ & $* \star \star$ & 0.64 \\
\hline STERLING & $5.910 \mathrm{E}-11$ & $* * \star$ & $4.770 \mathrm{E}-07$ & & 0.624 & GOYA & $7.950 \mathrm{E}-05$ & $* * *$ & 8.867E-03 & $* * \star$ & 0.972 \\
\hline BRAVO & $9.540 \mathrm{E}-11$ & $* * *$ & $6.710 \mathrm{E}-07$ & & 0.725 & ERNTE & 2.604E-04 & $* * *$ & $2.387 \mathrm{E}-02$ & $* * *$ & 0.813 \\
\hline EL PAIS & $2.460 \mathrm{E}-10$ & $* * *$ & $1.810 \mathrm{E}-06$ & & 0.243 & LOOK & $9.360 \mathrm{E}-05$ & $* * *$ & $9.014 \mathrm{E}-03$ & $* * *$ & 0.805 \\
\hline DUNHILL & $6.130 \mathrm{E}-06$ & $* \star \star *$ & 3.065E-03 & $* \star *$ & 0.942 & GALA SOCIETY & $1.090 \mathrm{E}-04$ & $* * *$ & $3.701 \mathrm{E}-02$ & $* * *$ & 0.697 \\
\hline BASIC & $1.660 \mathrm{E}-05$ & $* * *$ & $7.852 \mathrm{E}-03$ & $* \star *$ & 0.584 & $\begin{array}{l}\text { VICTORIO \& } \\
\text { LUCCHINO }\end{array}$ & 2.112E-04 & $* \star *$ & $1.817 \mathrm{E}-02$ & $* \star *$ & 0.844 \\
\hline PEPE & $1.030 \mathrm{E}-05$ & $* * *$ & $4.881 \mathrm{E}-03$ & $* \star *$ & 0.826 & FREE JACK & $5.300 \mathrm{E}-05$ & $* * \star$ & $6.421 \mathrm{E}-03$ & $* \star *$ & 0.733 \\
\hline GITANES & 7.180E-06 & $* * *$ & 3.397E-03 & $* * *$ & 0.909 & KANE & 1.720E-08 & $* *$ & $2.170 \mathrm{E}-05$ & & 0.438 \\
\hline LARK & $5.550 \mathrm{E}-06$ & $* * *$ & 2.777E-03 & $* * *$ & 0.974 & POOL & $5.090 \mathrm{E}-04$ & $* * *$ & $5.268 \mathrm{E}-02$ & $\star \star \star *$ & 0.891 \\
\hline PUEBLO & $8.490 \mathrm{E}-11$ & $* * *$ & $6.070 \mathrm{E}-07$ & & 0.801 & DJARUM & $1.010 \mathrm{E}-08$ & & $5.940 \mathrm{E}-06$ & & 0.629 \\
\hline BERKELEY & $1.500 \mathrm{E}-05$ & $* * *$ & $6.529 \mathrm{E}-03$ & $* * *$ & 0.823 & ZIGGY & $7.020 \mathrm{E}-05$ & $* * *$ & $1.171 \mathrm{E}-01$ & $* \star *$ & 0.913 \\
\hline EMBASSY & $1.460 \mathrm{E}-05$ & $* * *$ & $6.348 \mathrm{E}-03$ & *** & 0.854 & CARNIVAL & $7.080 \mathrm{E}-06$ & & $4.670 \mathrm{E}-02$ & $* * *$ & 0.645 \\
\hline VANTAGE & $6.710 \mathrm{E}-05$ & $* * *$ & $3.509 \mathrm{E}-02$ & $* * *$ & 0.717 & GLOBAL & 4.250E-11 & & $1.608 \mathrm{E}-01$ & $\star * *$ & 0.739 \\
\hline CONDAL & $1.030 \mathrm{E}-05$ & $\star * *$ & $4.430 \mathrm{E}-03$ & $* * *$ & 0.987 & ESSENTIAL & $1.060 \mathrm{E}-08$ & $\star * *$ & $9.720 \mathrm{E}-06$ & & 0.187 \\
\hline DUCAL & $4.250 \mathrm{E}-06$ & $* * *$ & $1.872 \mathrm{E}-03$ & $* * *$ & 0.664 & BRITISH HERITAGE & $6.180 \mathrm{E}-05$ & & $5.092 \mathrm{E}-03$ & & 0.307 \\
\hline COHIBA & $2.280 \mathrm{E}-09$ & & $6.240 \mathrm{E}-06$ & & 0.815 & YUMA & $2.310 \mathrm{E}-08$ & & $1.498 \mathrm{E}-01$ & $\star * *$ & 0.809 \\
\hline BELGA & $2.490 \mathrm{E}-05$ & $* * *$ & $8.100 \mathrm{E}-03$ & $* * *$ & 0.886 & PROGRESS & 5.407E-04 & $* * *$ & $3.713 \mathrm{E}-02$ & $* * *$ & 0.944 \\
\hline GAULOISES NEGRO & $3.780 \mathrm{E}-06$ & $* * *$ & $1.679 \mathrm{E}-03$ & $* * *$ & 0.93 & MERILYN & $4.930 \mathrm{E}-05$ & & $2.429 \mathrm{E}-02$ & & 0.54 \\
\hline
\end{tabular}

Note: The significance of the estimated parameters is given next to each estimation: ${ }^{*} 5-10 \%$; ${ }^{* *} 1-5 \%$; ${ }^{* *}<1 \%$. 